\title{
SOME RELATIONS OF THE BRAIN AND OF THE OLFACTORY APPARATUS TO THE PROC- ESSES OF IMMUNITY *
}

\author{
HENRY SEWALL, M.D. \\ DENVER
}

'The body is provided with three obvious lines of defense against infection, namely, its peripheral epithelium, its blood and lymph, and its tissue cells. The activity of modern investigators has been engrossed almost wholly with study of the last two; the first has received very little attention. Yet it is indisputable that the epithelial covering of the body must have intrinsic resources of protection against adverse influences which are in such habitual action that its relations should be considered truly physiological, rather than pathological, as its response to adventitious agencies would be. In short, a study of the pathologic physiology of the peripheral epithelium must conceive of it primarily as a mechanism for the prevention of disease rather than, as in the case of the body-fluids and tissues, an establishment for producing the means of cure. While the protoplasm of the surface cells must be endowed with a degree of autonomy involving capacity for independent response to irritation, which possibly includes the production of specific antibodies, its striking peculiarity is its abundant supply of sensory nerves, largely endowed with "specific energy," through which every external stimulus is made to provoke an immediate and universal internal response.

The incitement to the investigation the report of which follows was a desire to develop the existence of some immunological relations between the peripheral and the central mechanisms. If a priori conceptions are given undue prominence at the outset, a measure of defense may be found in the wise dictum of Richet, ${ }^{1}$ that in biologic research the guiding thread must always start from the teleologic point of view.

Modern therapeutics offers abundant illustration of the beneficent influence of physical agencies acting externally. The criterion for the usefulness of cold water in the treatment of typhoid fever is the "physiological response" which its application may provoke. As Chantemesse points out, the hydriatric stimulus probably does not excite the formation of specific antibodies against the invading noxa, but it seems probable that the capacity for the formation of antibodies is enhanced indi-

* Submitted for publication Dec. 17, 1913.

1. Richet, Charles: Ann. de l'Inst. Pasteur, 1907, xxi, 497. 
rectly, through reflex excitement of the various motor and metabolic mechanisms. Similarly, the benefits of the open-air treatment in tuberculosis are in some way due to physiological response to external agents, which, as in another place I have attempted to show, exert their influence largely through the temperature nerves of the skin. There is good reason to believe that at least the vital capacity for the formation of antibodies is largely under the control of external stimuli which make up the environment of what is known as the "hygienic life." The fact that tuberculosis finds least resistance to its development in the tissues of those who, like the American Indians, from a habitual open-air life are suddenly forced to conform to the restraints of civilization, argues that hygienic living produces no specific antibodies against this disease.

But there is abundant clinical evidence that a great variety of antigens can produce specific anaphylactic systemic response when applied to the peripheral epithelium. The assumption that such antigens must be absorbed into the circulation before becoming effective, while probably correct in general, is unwarranted without direct evidence. The urticarias and other anaphylactic phenomena following the ingestion of certain articles of food by some people, and, especially, the asthmatic paroxysms induced by the inhalation of certain odors, belong to one of the most interesting divisions of clinical pathology. Indeed, it was an incident related to me by V. C. Vaughan, Jr., of Detroit, which gave the final impulse to the present investigation.

Vaughan's account is as follows: The patient was a man, aged 36, who was suffering from moderately advanced tuberculous disease of the lungs complicated by recurrent hemoptyses. From March 11 to 13, inclusive, the patient received three injections of fresh, normal rabbit's serum of 0.1 c.c., 9 c.c. and 10 c.c. April $\%$, twenty-seven days after the first injection, a rabbit was brought into the patient's room, was handled by him and allowed to run about the bed. Between three and five hours after this event the patient suffered an asthmalike attack - the first which he had ever experienced.

As indicated at the outset, my conception in the main has been that phenomena which are essentially anaphylactic form a conspicuous feature of normal sensory activity. The mysterious ability of the hound to follow a definite trail unconfused by a multitude of other footsteps is cleared up at once if we assume that the dog's olfactory apparatus is sensitized to the odor which he follows. One is tempted to suggest that even the phenomena of complementary color sensation, as manifested in the "after-images," are but the psychic signs of specific antibodies formed in the retina.

The experiments to be described were performed on guinea-pigs. Sensitization was achieved by subcutaneous injection of normal horse- 
serum obtained from a commercial source. The sensitizing dose usually varied from 0.25 to 0.5 c.c. The toxic injection was invariably given through the jugular vein. Many intracranial operations were performed, including cutting the olfactory nerves or ablation of the olfactory lobes alone or with a certain bulk of the anterior cerebrum. Anatomically the guinea-pig is excellently adapted for such work. As is well known, the anatomical relations of the sense-organ for smell are almost unique.? It is constructed peripherally of nerve-cells inclosed within the olfactory mucous membrane. Processes directed distally from the nerve-cells project freely like bristles from the free surface of the membrane, while from the opposite poles "teledendrons" find their way into the cranial cavity to embrace the nerve-cells of the olfactory lobes.

This research would have been quite impossible but for the devoted aid given by my colleague, Dr. Cuthbert Powell, who has freely lent his surgical skill to the performance of the many scores of surgical operations inrolved in the investigation.

\section{GUINFA-PIGS SENSITIZED TO HORSE-SERUM MAY BE DESENSITIZED BY SOJOURN IN A HORSE STABLE}

The first effort made was to elicit some sign of anaphylaxis in the peripheral epithelium of a serum-sensitized animal. A guinea-pig, which had received a subcutaneous injection of horse-serum thirty-eight days before, was held gently on its back and horse-serum in droplets was allowed to fall into each nostril. I expected to witness some sign of specific irritation. The result, however, was wholly negative. The animal a few hours later received an intravenous injection of 0.5 c.c. of horse-serum and died in about three minutes with characteristic symptoms. Another sensitized pig was made to inhale finely vaporized serum, in the manner to be described later, but, as in the first case, the results were negative. These observations were repeated on numerous occasions with different animals and the results all pointed to the conclusion that guinea-pigs sensitized by subcutaneous injections of horseserurn manifest no particular irritation when the same serum is instilled into the nose or given by inhalation.

It then occurred to me that possibly the aroma of the animal producing the sensitizing antigen might develop some characteristic reaction. Accordingly, four guinea-pigs were placed in a box covered with wire netting. Two of the animals were normal and two, forty days previously, had each received subcutaneously from 0.5 to 0.75 c.c. of serum. The box was carried, July 7 , to a livery stable in which a score or more of horses were maintained. The air of the stable at this time was powerfully impregnated with a characteristic odor and there

2. Troland: Am. Jour. Physiol,, 1913, xxxii, 19. 
was a particularly pungent quality to the smell. Later in the season, as cooler weather advanced, the intensity of the odor diminished and its pungent quality disappeared. There was, as will be seen directly; a coincident change in the biological reactions. The box had been in the stable possibly five minutes when marked nervous disturbances were manifested by the two sensitized animals. One of them, a female weighing $480 \mathrm{gm}$, showed marked excitement, dashing about the box and biting at her companions, then scratching the nose vigorously. These symptoms subsided in about half an hour. The other sensitized pig, weight $195 \mathrm{gm}$., lay prone or squatted on the floor of the box and emitted plaintive sounds. The animals were kept in the stable overnight and appeared wholly normal when removed next morning. The control animals showed no particular disturbance.

Some drops of serum were instilled into the nostrils of the smaller sensitized pig and provoked within a few moments somewhat the same reactions as the animal had manifested in the stable. This experiment was, under these conditions, unfortunately not repeated. More than twenty-four hours after its introduction into the stable and about eight hours after its removal therefrom, the larger sensitized pig was given by the vein nearly 1 c.c. of horse-serum. There was no marked reaction; soon after its release from the holder the animal fed as usual. Twentyfive days later this pig received another intravenous injection of serum and died within four minutes. The smaller of the two sensitized pigs received its toxic dose some twenty-eight hours after removal from the stable. Owing to difficulties in manipulation a great excess of serum was injected into the vein, probably more than 1 c.c. The animal did not suffer the usual shock, but died from respiratory failure in about half an hour; its lungs were almost completely collapsed when the chest was opened.

In the light of later observations I am inclined to think that this animal's death was a sign of the passing of the phase of antianaphylaxis induced by inhalation of stable-air combined with the excessive magnitude of the toxic injection. No effort was spared, of course, in seeking a solution of the results obtained in these preliminary experiments. Of fundamental importance appeared to be the question whether the desensitizing agent in the air of the stable affected the body indirectly through action on the olfactory mucous membrane or was absorbed directly through the respiratory tract. To resolve this question, groups of pigs, sensitized or normal, were operated on for section of the olfactory nerves. Under ether, a small hole was trephined just posterior to the cribriform plate, the nerves were cut with a fine bistoury and their stumps wiped out with a small pledget of cotton held in forceps. The animal manifests little or no disturbance after such an operation. 
In other animals not only the olfactory nerves were removed but the olfactory lobes as well. But, for reasons that will be detailed later, this more extensive operation was necessarily performed only on normal, non-sensitized animals. The experimental data are condensed in the following protocols:

Expertment 1.-Four sensitized guinea-pigs, two with intact olfactories, exposed to stable August 18.

Pig 1, male, $480 \mathrm{gm}$.; olfactory nerves excised July 12; sensitized with serum July 16. No reaction in stable.

Pig 2, male, $645 \mathrm{gm}$.; sensitized July 16; olfactory nerves excised August 15. Restlessness after twenty minutes in stable.

Pig 3, male, 675 gm.; unoperated, sensitized July 16. Much erotic excitement after fifteen minutes in stable.

Pig 4, male, 750 gm.; unoperated, sensitized July 16. No reaction except slight uneasiness after forty minutes in the stable.

After remaining all night in the stable each animal received, August 19, an intravenous injection of more than 0.5 c.c. of fresh serum. Every pig died in characteristic shock except Pig 3, which responded to the injection with violent struggles, some respiratory râles, deepened respiration and rubbing of the nose when released. After this moderate shock the pig completely recovered.

One cannot fail to connect the excitement of this pig when exposed to the stable air, attempting to copulate with his male companion, etc., with the desensitization certified by the development of antianaphylaxis. This animal was reexposed in the stable thirty-three days later, when he showed but slight excitement, and the following day he succumbed to intravenous injection.

Experiment 2.-Two pigs received subcutaneous serum July 16. Exposed in stable August 20.

Pig 1, male, $525 \mathrm{gm}$. Olfactories intact. Within five minutes after entering stable is erotic and continues restless, scratches nose, etc., for an hour.

Pig 2, male, $540 \mathrm{gm}$. Olfactory nerves had been cut July 12, and a serum inhalation given August 16. In the stable is restless, slightly dyspneic and scratches chin during an hour.

August 21, intravenous injection of serum, more than 0.5 c.c., was given to each. Pig 1 had two slight spasms, sneezed twice and then recovered. Pig 2 showed rery little reaction. Result, antianaphylaxis in both animals.

The recovery of the second animal would appear to show that the olfactory apparatus was not concerned in the desensitization, but on August 22, its brain was exposed for the purpose of excising the olfactory lobes; it was then found that the olfactory nerves appeared to have regenerated in the interval of thirty-nine days elapsing between the nerve section and the stable exposure. 
Experiment 3.-Two pigs sensitized July 16. Both had been in the same box with the animals used in a former experiment. They were placed again in the stable for forty minutes, August 22. Twenty hours later they received the toxic injection.

Pig 1, male, $660 \mathrm{gm}$. Somewhat erotic and restless in stable.

Pig 2, male, 360 gm. Olfactory nerves cut July 12 . Restless and rubs nose in stable.

Both died from the toxic injection, which, it will be noted, was given twenty hours after leaving the stable, whereas the usual interval was two or three hours. Necropsy on Pig 2 indicated partial regeneration of the olfactory nerves.

Experiment 4.-Two pigs sensitized July 16. Placed in stable for five hours, August 25.

Pig l, 425 gm.; a comparatively feeble animal. Restless, rubs nose and scratches in the stable.

Pig 2, $790 \mathrm{gm}$.; olfactory nerves were cut, August 24. Less excitement shown in the stable than in the case of Pig 1.

Intravenous injections of more than 0.5 c.c. of serum were given within an hour of removal from the stable. Pig 2 died promptly from shock. Pig 1 showed no reaction except for temporary muscular weak. ness becoming apparent in an hour. This animal was undoubtedly antianaphylactic but was found dying the next morning after exposure to the cold of the previous night. It was frequently noted that guineapigs recovering from the strain of anaphylactic shock are exceedingly non-resistant to external cold. Their temperature regulation is apparently profoundly disturbed. ${ }^{3}$

It is unnecessary to go further into detail along this line of evidence. Suffice it to say that a large proportion of guinea-pigs sensitized subcutaneously to horse-serum were desensitized by exposure to the air of the horse-stable. There was a very obvious relation between the pungency of the stable-odor and the latent period of anaphylactic disturbance. When the smell was most intense the nervous symptoms of anaphylaxis came on almost immediately. In Denver the nights became strikingly cool in August so that the more intense stable-odor only endured for two or three weeks in July and the time required to sensitize guineapigs did not allow of prolonged investigation under conditions most favorable to olfactory stimulation.

As the mean temperature of the air fell and the stable odor became less intense the latent period of anaphylactic disturbance increased from a very few minutes to a quarter of an hour, then to longer periods and finally the onset of disturbance could not be distinguished. Nevertheless sensitized pigs kept in the stable for a day or more sometimes

3. Doerr: In Kolle and Wassermann's Handbuch des pathogenen Mikroorganismen, 1913, ii, Part 2. p. 1070. 
proved to be antianaphylactic to intravenous injection even when they had manifested no striking symptoms marking desensitization.

All the earlier observations pointed to the conclusion that only pigs possessing intact olfactory mechanisms were subject to desensitization through the stable air. Obviously a single positive result demonstrating antianaphylaxis in the case of a smell-free guinea-pig would show that the noxa producing desensitization could affect the body through channels other than the olfactory. Such a demonstration was afforded by observations on four animals kept in the stable for three days during the first week in October. Each had suffered either recent section of its olfactory nerves or loss of both olfactory nerves and lobes many weeks previously. Submitted to the test of intravenous inoculation, one of the pigs whose olfactory lobes had been excised thirty-nine days before and which had been sensitized by subcutaneous serum thirty-six days before, recovered from the toxic injection after slight symptoms of shock.

This section of my work may be briefly summarized by stating that fourteen sensitized guinea-pigs with intact olfactory sense were exposed to the stable air. Of these, five became completely antianaphylactic to the intravenous toxic injection and two succumbed only after evidence of great resistance to the toxic dose. The fourteen pigs included two that had been previously made antianaphylactic as witnessed by recovery from an intravenous injection; both died from the second intravenous dose. The fourteen pigs also included two in which the olfactory nerves had been cut long before but which seemed to have regenerated.

Ten sensitized pigs were exposed in the stable after recent section of their olfactory nerves or long-standing ablation of the olfactory lobes. None of these had manifested any marked symptoms of anaphylactic disturbance in the stable. Only one of this group survived the toxic intravenous injection.

Daily contact with such phenomena as have been described is bound to give rise to certain more or less defensible impressions which have not been submitted to definite proof. Of this nature are the notions that the desensitizing agent in the stable-air operates on the body in two ways: (1) acutely, as an odor irritating the olfactory nerves with the production of anaphylactic symptoms; (2) more slowly, by absorption through the respiratory tract, without the production of striking anaphylactic symptoms. The important question as to whether antianaphylaxis can be produced by the mere odorous stimulation of the olfactory epithelium has not been settled, although the facts seem to point in that direction. The phase of antianaphylaxis in these experiments, as found in other fields, comes on very soon after exposure to the exciting cause. Also, several experiments pointed to the conclusion 
that the antianaphylactic period is very short - that it is rapidly vanishing within twenty-four hours after removal from the desensitizing environment.

The theory having been proved that fully developed sensitization could be temporarily undone by exposure of animals to stable air, the conclusion seemed obvious that sensitization should be altogether prevented in pigs kept in the stable during the latent period of sensitization. The result of an appropriate experiment proved, however, directly the contrary, as follows:

Experiment 4.-Five guinea-pigs, weighing about $350 \mathrm{gm}$. each, were placed in the stable October 24, about twenty hours after receiving subcutaneous injections of serum, with the exception of one animal which had received an injection ten days before. This last pig was taken from the stable October 29, that is, fifteen days after its sensitizing injection and at the end of five days' residence in the stable. An intravenous injection given at this time was fatal within four minutes. The remaining four pigs were taken from the stable November 17, after exposure of fourteen days, and each succumbed to an intravenous injection within about three minutes. Necropsy was performed on these, as in all other fatal cases, and the lungs were found in characteristic anaphylactic distention. Guineapigs of this group manifested a somewhat striking difference in behavior from all other animals exposed in the stable. They never recovered from the timidity associated with the change of environment, nor did they acquire a normal appetite for food. The results of the experiment indicate that, at least in cool weather, the processes leading to sensitization go on in the environment which may effect desensitization of a fully sensitized animal.

\section{SENSITIZATION TO HORSE-SERUM IS NOT CAUSED BY EXPOSURE} TO STABLE AIR

As to the nature of the agent producing the desensitizing effects, I have no definite evidence. When the box containing the guinea-pigs was held directly under the nose of a horse, or when the manureimpregnated straw of the stable was placed within it no particular reaction was observed. An effort was made, of course, to sensitize the guinea-pigs to horse-serum by the same influence which caused their desensitization.

The two normal pigs which had been used as controls and exposed to stable air, July $\%$, each received an intravenous injection of 0.5 c.c. of horse-serum sixty-three days later. There was nothing like shock to be discerned, though one of the animals rubbed its nose vigorously ten minutes after its release, the other seemed sleepy and both preened the body as if stimulated by itching.

Four normal male pigs, weighing about $390 \mathrm{gm}$. each, were placed in the stable, September 9 . One of them was removed after twenty-four hours and within an hour thereafter received an intravenous injection. There was no reaction except that the animal remained rather unusually quiet. For fourteen days the remaining pigs were kept in the stable, 
two of them being taken out for some hours each day. One of these and the third pig - which had been continuously in the stable - were given intravenous injections within about an hour after removal, with completely negative results. The evidence shows that while the possibility of minor degrees of sensitization to toxic injections of serum cannot be denied, nothing like the sensibility leading to fatal shock is induced." The slighter degrees of anaphylactic reaction are somewhat uncertain in significance since the normal pig is prone to manifest the same actions, such as nose-rubbing and preening the body.

\section{ANAPHYLACTIC SHOCK AND DESENSITIZATION CAUSED BY OPERATIONS ON THE BRAIN OF THE SENSITIZED GOINEA-PIG}

According to the well-known views of Besredka, ${ }^{5}$ sensitization in the guinea-pig is primarily or wholly a property of the brain. This author holds the view that during the process of sensitization the body tissues form a substance une sensibilisine, which fixes itself to the brain-cells. Intracerebral injection of a large dose of serum (0.25 c.c.) produces rapid desensitization with great shock or death. With small intracerebral injections $(0.0025$ c.c. to 0.025 c.c.), desensitization of the cerebrum comes gradually and the animal becomes antianaphylactic. The animal is resensitized by a new injection made within this period. He holds that the condition of antianaphylaxis is a return to the normal state. Guinea-pigs may be desensitized by intracerebral injections but cannot be sensitized thereby, that is, the brain-cells cannot prepare the sensitizing substance. In an animal thoroughly narcotized by ether, the intracerebral injection of serum produces no shock but still induces antianaphylaxis.

That brain sensitization cannot altogether account for the phenomena of anaphylactic shock was sufficiently demonstrated by Auer and Lewis, ${ }^{6}$ who found that sensitized guinea-pigs were killed by intravenous injection and showed characteristic distention of the lungs after section of the vagi nerves and after destruction of the base of the brain, medulla and spinal cord. That the irritability of the brain is profoundly modified by the state of sensitization was early made clear in our experiments.

In attempting to remove the olfactory sense from sensitized pigs in preparation for the stable experiments, it was found that while intracranial section of the olfactory nerves produced no particular reaction,

4. Not until this work had been long completed did I learn that Rosenau, in an announcement I have not been able to trace, describes successful efforts to sensitize guinea-pigs in a horse stable.

5. Besredka, A., and Steinhardt, E.: Ann. de l'Inst. Pasteur, 1907, xxi, 117 ; Besredka, A.: Ann. de l'Inst. Pasteur, 1907, xxi, 777 and 950; ibid., 1910, xxiv, 273,879 , etc.

6. Auer and Lewis: Jour. Exper. Med., 1910, xii, 151. 
abiation of the olfactory lobes caused profound disturbance, as illustrated in the following experiment:

Experiment 5.-Four guinea-pigs, about $730 \mathrm{gm}$. each, were given subcutaneous injections of 0.33 c.c. of serum, July 16. August 15 , under light ether anesthesia, the olfactory nerves were cut and wiped out in three animals; there was no special reaction. In the fourth pig, which received the least ether, both olfactory lobes and nerves were removed. After its release the animal continued to lie on its side and in about fifteen minutes severe clonic convulsions of the limbs appeared, lasting half an hour or more. The animal gradually recovered, but more than two hours after the operation manifested rhythmic "bucking" movements of the body without the feet leaving the floor. Next day this animal was well and was given 0.75 c.c. of serum intravenously; there was no reaction except for slight torpor. One of the first three pigs was given a like injection immediately afterward and died within three minutes.

It should be said that removal of the olfactory lobes in a normal guinea-pig produces no definite response. The shock and subsequent antianaphylaxis described are no special effect of removal of the olfactory lobes, but follow mutilations of the cerebrum, thus:

Experiment 6.-A vigorous male pig, $700 \mathrm{gm}$., was sensitized July 16. August 23, under ether, an amount of cerebral tissue in bulk about that of the olfactory lobes was removed from the parietal regions. The animal when released continued for ten minutes to lie on its side with clonic twitching of the hind legs. The next day this pig received an intravenous injection of 0.75 c.c. of serum and, with the exception of slight asthmatic wheezing, showed no special reaction.

EXPERIMENT 7.-Male pig, 780 gm., sensitized August 14. August 21, a bulk of cerebrum in size five or six times that of the olfactory lobes, was removed. For nearly an hour the pig lay on its side with clonic twitchings, increasing to convulsions, of the legs. It sprang up and bucked after sitting up and then for many hours carried on continuous coordinated forced movements, seeking always to escape restraint and wander forward. The next morning the animal was found dead. The fatal result was probably brought about partly by failure to react to the lowered temperature of the night air.

Numerous experiments of like character have definitely proved that anaphylactic shock is caused by mutilation of the brain in the sensitized guinea-pig. The degree of shock seems rather strictly related to the amount of cerebral tissue removed, but varies somewhat in different animals. The intensity of shock suffered after a definite nerve injury seemed to diminish as the weather became cooler. If this impression is confirmed it may be elucidated by the facts portrayed in the next section of this paper. In the accounts ${ }^{7}$ of anaphylactic shock and the resulting phase of antianaphylaxis usually given, the phenomena have been induced by reinjection of the antigen which caused sensitization, but here are examples of profound somatic changes being induced by mere ablation of brain-tissue in amounts whose loss would cause no particular disturbance in a normal animal. In seeking an explanation

7. Doerr: In Kolle and Wassermann's Handbuch der pathogenen Mikroorganismen, 1913, ii, Part 2, p. 1085. 
for the facts it seemed probable that the effective stimulus consisted in the mechanical agitation of the brain. To test this view an electric vibrator, designed for therapeutic massage, was used, its flat ebonite disk, rapidly oscillating, being firmly applied for three minutes to the skulls of a series of sensitized guinea-pigs which were slightly etherized. The results showed a curious discrepancy.

Experimest 8.-A guinea-pig previously described, which had received a subcutaneous injection of serum July 16, had lost part of its cerebrum August 23, and had recovered from an intravenous injection August 24, was submitted to skull vibrations September 22. The only reaction to the vibration was rubbing of the nose and a slight "steppage" movement. September 23 more than 0.5 c.c. of serum was given intravenously, resulting in dyspnea, peristalsis and cough, but recovery within an hour. (This animal received another vibration November 9 , followed by intravenous injection November 11, from which it recovered. Another intravenous injection was given fourteen days later with recovery, and a fifth injection into a vein was made December 9, without producing symptoms. This is a case of either prolonged antianaphylaxis or permanent immunity.)

Experimext 9.-Guinea-pig, male, $820 \mathrm{gm}$., sensitized July 16. From August 16 to August 31 it received five inhalations of vapor of horse-serum without effect. September 2 the electric vibrator was applied to its skull for about five minutes. There was no reaction except "steppage" movements, nose rubbing and slight incoordination. The next day the animal received intravenously 0.75 c.c. of serum and fully recovered with very slight symptoms. (Twenty days later the olfactory lobes were removed. The shock was very intense. The animal never fully recovered, though it would eat greedily; it died four days after the operation.)

The results of subsequent experiments indicate that desensitization caused in the foregoing animals by vibration of the skull was dependent in some way on the treatment they had previously received auxilliary to the primary sensitization. Five other guinea-pigs, two of which had been sensitized intravenously, were submitted to vibration and all died in shock when injected the following day by the vein. Two of the animals before the toxic injections received no less than six vibrationtreatments at intervals of two days. The application of the vibrator to the skull is exceedingly drastic treatment and frequently resulted in complete inhibition of the respiration and great slowing and enfeeblement of the heart-beat.

The phase of antianaphylaxis produced by the shock of brain operations is very short. It passes off in less than forty-eight hours, as was evidenced by three special experiments which it is not necessary to detail. That no shock is occasioned by moderate ablation of nervous tissue in the normal pig is shown by the following:

EXPERIMENT 10.-Normal male, $360 \mathrm{gm}$. Olfactory lobes and a portion of the anterior cerebrum slightly greater in bulk were removed November 3 . There was no reaction whatever. (In two days this pig sickened, probably from infection, and died in a week. Other normal pigs suffered loss of much greater quantity of brain without permanent disturbance). 
In a widely quoted paper, Schürer and Strasmann ${ }^{8}$ describe experiments in which they attempt to contravert Besredka's idea that the sole seat of the anaphylactic reaction is in the brain. They excised the whole brain, including the basal ganglia, in sensitized guinea-pigs and then gave them serum by intravenous injection. The animals died within a period varying from a few minutes to several hours, and the results were supposed to contravert the theory that the brain is involved in anaphylactic phenomena. In the light of $\mathrm{my}$ observations it is plain that such methods are necessarily incompetent to clear up the subject.

\section{DESENSITIZATION OF THE BRAIN THROUGH SECTION OF THE OLFACTORY NERVES}

On one occasion, the olfactory lobes were removed from a fully sensitized guinea-pig but the animal manifested no sign of shock whatever. In seeking the cause for this departure from the rule that had seemed established, it was found that this pig had, eight days before, been subjected to section of its olfactory nerves. It at once became necessary to follow out the suggestion aroused by this development.

EXPERIMENT 11.-Six young pigs, weighing about $270 \mathrm{gm}$. each, were sensitized by subcutaneous injection August 29. From four of these, Pigs 1, 2, 3 and 4, the olfactory nerves were cut and wiped out September 16, under very slight etherization. There was no reaction except to a very slight degree in one (Pig 2) in which bleeding occurred through the nose due to injury to the cribriform plate. September 24, twenty-six days after subcutaneous injection, the olfactory lobes were removed from Pigs 1,2 and 5 (the latter having intact olfactory nerves). Pigs 1 and 2 showed no shock; Pig 5 lay on its side for nearly ten minutes with somewhat convulsive clonic trembling of the legs. This shock did not produce antianaphylaxis for the animal succumbed to intravenous injection the next day. September 25 the olfactory lobes were excised from Pig 3. There was no shock whatever, the animal sitting up at once when released, though it rubbed its nose and preened the body. On the same date there were taken from Pig 4 (olfactory nerves destroyed September 16), both the olfactory lobes and a portion of the anterior cerebrum, about equal in bulk to the combined olfactory lobes. The animal lay quietly on its side for two minutes after release from the holder, breathing hard but without convulsive movements, and then sat up with normal appearance except for slight temporary spasmodic nodding of the head. No antianaphylaxis was produced, for the animal succumbed to an intravenous injection the next day, September 25. Pig 6, sensitized but with intact olfactory nerves, was made to lose its olfactory lobes and a portion of the anterior cerebrum equal to a single olfactory lobe. When released this animal lay on its side for five minutes with elonic convulsions. It then sat up and appeared normal for awhile, but soon became restless and the subject of forced movements, which continued until the animal died in convulsions, attended with enormous erections of the penis, after six hours. At necropsy the lungs were found collapsed, containing a few hemorrhagic areas but no consolidation.

8. Schïrer, J., and Strasmann, R.: Ztschr. f. Immunitätsforsch., 1912, xii, 143. 
The experiments show very definitely that in sensitized guinea-pigs the nervous shock following mutilation of the brain is greatly reduced eight or ten days after section of the olfactory nerves. It was sought to determine how soon such desensitization of the brain followed on nerve section, and how long it continued.

-Experiment 12.-Pig 1, male, 440 gm., sensitized August 29. Olfactory nerves destroyed September 24. Next day the olfactory lobes were removed. The animal manifested moderate but decided action, such as relatively slow recovery from the operation followed by nose-rubbing and clonic tremblings of the body. The shock was not sufficient to produce antianaphylaxis for the pig succumbed in three minutes next day to toxic injection.

Pig 2, female, $910 \mathrm{gm..}$ far advanced in pregnancy, sensitized August 29. Olfactory nerves cut November 5 . November 6 the olfactory lobes and a like bulk of cerebrum were removed. There was scarcely any shock following the operation, the only sign of anaphylaxis being a slight inspiratory humping of the body setting in ten minutes after release.

These results indicate that while the desensitizing effect of olfactory nerve section on the brain may develop within a day, the full influence of the deprivation of olfactory stimuli is not established with certainty till later.

Experiment 13.-Male pig, $500 \mathrm{gm}$., sensitized August 29. Olfactory nerves cut November 5. November 18 excised olfactory lobes and a similar bulk of cerebrum. The animal lay quiet for nearly ten minutes after release and then sat up with no evidence of reaction except for slight rhythmic lifting of the legs. Next day the pig succumbed in three minutes to the toxic injection.

It is clear from these experiments that the diminished sensibility of the brain following section of the olfactory nerves in sensitized guinea-pigs may be well marked within twenty-four hours and remains in full force for at least thirteen days. After longer periods there may always be suspicion of regeneration of the olfactory nerves. In the following experiments part of the cerebrum was removed long after ablation of the olfactory lobes:

Experiment 14.-Female pig, $690 \mathrm{gm}$. Olfactory lobes removed August 27 and the space left filled with melted paraffin (in none of several cases in which this was done could the paraffin be detected with certainty after several weeks). Serum was injected subcutaneously August 29. November 3, sixty-eight days after removal of the lobes, under slight ether anesthesia, there was scooped from the anterior cerebrum an amount of tissue estimated as about twice the bulk of the normal olfactory lobes. There resulted moderate but distinct shock, with some forced movements, which passed off after about thirty minutes. Two days later the animal withstood an intravenous injection of nearly 0.5 c.c. of serum with scarcely any reaction.

This experiment indicates that after removal of the olfactory lobes (of course including the attached nerves) the sensitiveness of the brain to laceration has been more or less completely restored in about two months. Similar conclusions were derived from other experiments the 
conditions of which were more complicated, which it is unnecessary to describe.

It might be claimed that the influence on the irritability of the brain apparently exerted by the olfactory sense is not a specific property of this sense but is wielded by any strong sensory impulse or is also a part of the function of other special senses. I did not fully grasp, until too late to sensitize new animals, the importance of testing the relation of the visual sense to cerebral irritability. A single experiment, however, went to show that the removal of one eye does not desensitize the brain as in the case after section of the olfactory nerves.

Experiment 15.-Male, $615 \mathrm{gm}$. Sensitized by intravenous injection of 0.5 c.c. of serum September 6. Under ether anesthesia left eyeball was removed November 6. November 10, under ether, the olfactory lobes and an equal bulk of cerebrum were removed. There was moderate but pronounced shock lasting for more than half an hour. The shock was not sufficient to protect the pig with antianaphylaxis when an intravenous injection was given next day.

From the results that have been described in the last two sections of this work it seems impossible to avoid the conclusion that sensitization of the brain and sensitization of the body represent different biologic conditions. The former is a labile, the latter a stabile, state. The threshold of irritability of the sensitized brain is plainly leveled in response to olfactory sensory stimuli. The brain may be completely desensitized without affecting in the least the response of the body to the second, toxic dose of the antigen. An attempt to elucidate the teleological significance of these coordinations will be made in the discussion at the end of this paper. As is well known, Besredka asserts that the intracerebral injection of 0.25 c.c. of serum will, in an unanesthetized sensitized guinea-pig, cause speedy anaphylactic death. If the conclusions drawn above as to desensitization of the brain following section of the olfactory nerves be correct, it should be possible for an animal so treated to resist Besredka's fatal injection. 'That this is true is proved by the following:

EXPeriment 16.-Pig 1, female, $360 \mathrm{gm}$., sensitized August 29. Olfactory nerves cut and wiped out September 16. September 26, under light ether anesthesia, a trephine hole was made over the cerebrum and there was injected through a hypodermic needle into both hemispheres a total of 0.25 c.c. of horseserum. The animal was practically out from under the influence of ether during the injection. There was but very slight reaction marked by restlessness and some jerking of the head. This animal weighed $450 \mathrm{gm}$. November 5 , when it received an intravenous injection and died in four minutes.

Pig 2, female, $840 \mathrm{gm}$., sensitized August 29. Olfactory nerves cut November 5. November 8 the skull was trephined over posterior cerebrum and the animal was released until entirely recovered from ether; then, as before, 0.25 c.c. of serum was injected into the brain. There was rather severe shock marked by clonic twitchings of legs, rapid breathing, circular movements, weakness of hind legs; gradual recovery after an hour or two. This shock was not sufficient 
to produce antianaphylaxis, for the animal succumbed next day in the usual way to intravenous injection.

Besredka found that intracerebral injections made with very small amounts of serum, or made under deep ether anesthesia, are not lethal, and the following day the animal is found to be antianaphylactic. Rosenau and Anderson ${ }^{9}$ repeated these experiments on etherized guineapigs and found that seven out of eight animals died from the second injection given next day. These discrepancies may be accounted for by supposing that the duration of the antianaphylactic state may be less as well as more than twenty-four hours.

According to the preceding argument, it should be suspected that ether narcosis affects only the susceptibility of the brain to shock, leaving that of the body unaffected. It was found, in fact, that a sensitized guinea-pig etherized to relaxation, died as quickly from intravenous injection of serum as one treated without an anesthetic. In the earlier experiments of this work the intravenous injections were all given without an anesthetic for fear of masking the anaphylactic symptoms; but in all the confirmatory tests the animals were subjected to a slight etherization, with little or no distortion of reactive symptoms.

Reference was made in the preceding section of this paper to an impression which developed as the result of prolonged experimentation, that the anaphylactic shock caused by the ablation of a definite mass of brain tissue became less intense as the weather turned cooler. Such a result might be expected if the olfactory sense, whose excitation probably varies with the external temperature, be indeed, a physiological regulator of brain irritability.

In his excellent contribution to the great work edited by Kolle and Wassermann, Doerr summarizes his discussion on the site of anaphylaxis thus: "That the real points of attack of the anaphylactic noxa lie in the periphery has been established beyond all doubt."

\section{THE RELATION OF THE OLFACTORY NERVES TO SHOCK IN THE NORMAL BRAIN}

The marked dependence of anaphylactic disturbance following operations on the brain of serum-sensitized guinea-pigs on integrity of the olfactory nerves raises the question whether in the normal animal there is not a specific physiological relation between the olfactory sense and irritability of the brain. The literature of cerebral physiology makes it obvious that so profound a problem can only be solved by a great

9. Rosenau and Anderson: Jour. Med. Research, 1908, xx, 37.

10. "Das die wesentlichen Angriffstellen der anaphylaktischer Noxa in der Peripherie liegen, ist heute wohl über allen Zweifeln sichergestellt." Doerr in Kolle and Wassermann's Handbuch der pathogenen Mikroorganismen, Ed. 2, ii, Part 2, p. 1078. 
number of guarded observations. Nevertheless, a few experiments were ventured in this field and the results were sufficiently positive to deserve record.

Five guinea-pigs were taken which were in very fair condition although they had been inoculated with what was evidently an attenuated strain of tubercle bacilli nearly three months before. In three of the animals the olfactory nerves were cut and two or three days later the olfackory lobes were excised together with a quantity of cerebral tissue estimated at three times the bulk of the lobes. In making this estimate the olfactory lobes were placed on a sheet of paper and three heaps of equal size, scooped from the anterior cerebrum, were laid near by. The operations were performed, as usual, under very light anesthesia. As will be seen, the symptoms of shock were much more pronounced in the two animals whose olfactory nerves remained intact up to the time of the operation.

Experiment 17.-Pig, 1, weight $600 \mathrm{gm}$. Excised olfactory nerves November 13. November 15 excised olfactory lobes and about three times their bulk of cerebrum. Pig when released lay for ten minutes apparently conscious, but with clonic tremblings of the legs and slight dyspnea. Recovered quickly; result, very slight reaction.

Pig 2, $485 \mathrm{gm}$. November 13 olfactory nerves cut. November 16 the olfactory lobes and part of the cerebrum removed as before. The animal lay quietly for six minutes and then sat up without reaction except for some dyspnea, noserubbing and rhythmic nodding of the head. Result, very slight reaction.

Pig 3, $510 \mathrm{gm}$. Olfactory nerves cut November 16. November 18 olfactory lobes and three times their bulk of cerebrum removed. Animal tried to sit up in six minutes after release. There were no convulsive movements, but the animal ran about the room and sought to hide in a dark corner. Normal but dull within an hour. Result, slight reaction as shown by apparently forced movements.

Pig 4, $510 \mathrm{gm}$. Olfactory nerves intact until time of the main operation November 15, when the olfactory lobes (with nerves) and three times their bulk of cerebral tissue were removed. Pig lay for more than ten minutes after release with clonic tremblings. It then turned on its back with convulsive doubling of the body. It was still unable to sit up in twenty minutes after which there was a convulsive twisting of the body with legs kicking. It soon recovered. Result, marked but moderate reaction.

Pig 5, about $580 \mathrm{gm}$. Olfactory nerves intact until main operation November 16, when the olfactory lobes and cerebral tissue were excised as before. Pig lay for ten minuntes after release with clonic tremblings of the legs; then there was a tetanoid twisting of the body. Sat up in twenty minutes and manifested epparently forced twisting movements. Within forty minutes the only disturbance was shown by rhythmic lifting of the body. Result, marked but moderate reaction.

In answer to the objection to the use of ether in these experiments it may be said that narcotization was of such light degree that animals in which the olfactory nerves alone were cut would sit up at once without reaction on release from the holder. When nerve-cell tissue was excised the animals lay on the side, with or without convulsive twitchings, for 
a period apparently proportional to the amount of substance removed; that is, the symptoms were a result of the operation, not of the anesthesia.

\section{INFLUENCE OF COCAINIZATION OF THE NOSE ON THE SHOCK FROM INTRACRANIAL OPERATION}

The suggestive surgical conceptions of Crile ${ }^{11}$ are recalled by these results and an effort was made to modify the shock of brain operations through an attempt to cocainize the olfactory mucous membrane. It is well known that a solution of cocain sprayed into the nose may completely abolish the sense of smell temporarily. Only a few unconvincing experiments were tried in this direction. A 2 per cent. solution of cocain was dropped into the nostrils of two sensitized guinea-pigs four times in the course of fifteen hours. Then under light ether anesthesia the olfactory lobes and a somewhat greater amount of cerebral tissue were removed from each, with resultant moderate but distinct reaction in each. The shock was much less and cleared up sooner than that which occurred in most sensitized pigs subjected to the same operation without cocain. Each of these animals succumbed next day to intravenous injection. Of four young pigs weighing about $240 \mathrm{gm}$. each, from a sensitized mother, two were treated with several nasal instillations of cocain. One of these pigs quickly died with symptoms to be detailed later. The other three were subjected to the loss of the olfactory lobes and about three times their bulk of cerebral tissue. There was decidedly less prolonged convulsive reaction in the cocainized pig than in the untreated pigs, though the former showed a high degree of nervous excitement. From the results of observations already detailed it is obvious that cocain anesthesia should be prolonged for a day or two in order to obtain its desensitizing action, if any, on the brain.

\section{CERTAIN ANALOGIES BETWEEN THE EFFECTS OF COCAIN POISONING AND ANAPHYLACTIC SHOCK}

Guinea-pigs were killed by nasal instillation of cocain and by subcutaneous and intravenous injection. Five unsensitized pigs were given intravenous injections of cocain in about 4 per cent. solution. Whether the poison was injected slowly or rapidly the result was the same, a speedy diminution in the amplitude of respiratory movement, and death without convulsion. The heart continued beating for many minutes after respiratory arrest just as it does in anaphylactic death. The lungs were found collapsed at necropsy.

11. Crile, G. W.: Boston Med. and Surg. Jour., 1910, elxiii, 893. 
Three young pigs, offspring of a sensitized mother, weighing 180 to $240 \mathrm{gm}$. each, were killed by the repeated instillation in the nose of a cocain solution of from 2 to 4 per cent. The symptoms of poisoning came on very suddenly. The animal would fall on its side; the head was tonically retracted; frequent and well-marked opisthotonus and clonic convulsions of legs and body occurred. The same series of events occurred when subcutaneous injections of cocain were given. This was done in the case of seven animals, four of which were serumsensitized, but the element of respiratory disturbance was more marked than when the poison was given by the nostrils. The retraction of the head was a characteristic symptom, the chest would be distended and the respiratory movements very rapid and so shallow as to be hardly visible. An animal might recover after remaining more than half an hour apparently in extremis. The convulsive phenomena witnessed in these animals were exceedingly suggestive of those seen in severe anaphylactic shock. But the particular object of these experiments was to follow out an observation that had been made on the pig from a sensitized mother, which had first succumbed to cocain by the nose. The lungs of this animal were found, post mortem, to be markedly distended, almost as much so as after anaphylactic shock. In two other cases this extraordinary post-mortem distention of the lungs was found, although usually the lungs were well retracted from the heart on the ventral side but maintaining apparently a condition of semiexpansion dorsally. In two normal guinea-pigs killed by cocain subcutareously the post-mortem lung-distention was less striking than in the sensitized or offspring of sensitized pigs. That the post-mortem distention of the lungs did not depend on the terminal convulsions seemed evidenced by the state of two sensitized pigs which were injected with strychnin; in these the lungs were found completely collapsed at necropsy. The expanded lung after death from cocain offers marked differences from the expanded lung after anaphylactic death. The former is pale, the latter congested. Both remain distended when excised, but the former crepitates little and collapses but slightly when squeezed in the fingers; the latter does both. In that minority of cases in which the lung remains distended after death by cocain, its behavior suggests a rubber-like structure. The phenomena described in this section recall the similar, though still more striking, effects described by Dale and Laidlaw ${ }^{12}$ as following the injection into guineapigs of betaimidazolylethylamin. They call attention to the anaphylactic-like changes produced by this substance.

12. Dale and Laidlaw: Jour. Physiol., 1911, xliii, 182. 
REACTIONS OF GUINEA-PIGS TO HORSE-SERCM ADMINISTERED THROUGH THE NOSE AND BY INHALATION IN SPRAYS: LOCAL

AND GENERAL ANAPHYLAXIS

Comparatively few investigations seem to have been made with a view to determining the effect of the application of antigens to the unaltered peripheral epithelium. The reaction to the tuberculin test of von Pirquet involves wounding of the outer skin. Administration of antigens by feeding, especially by means of the stomach-tube, greatly complicates the experimental conditions. In an important paper, Dserzgowsky ${ }^{13}$ describes experiments in which plugs of cotton wool moistened with the toxin of diphtheria were applied to the mucous membrane of the nose and the toxin itself to the general respiratory tract through the inhalation of sprays. Experiments were performed on horses and on the author himself. It was asserted that in these ways active immunity, both local and general, could be harmlessly induced. Blumenau., ${ }^{14}$ following this suggestion, inserted for thirty minutes tam. pons moistened with diphtheria toxin, diluted to one-third strength, into the nostrils of children. After twenty such treatments diphtheria antitoxin was found in the blood. Practically the same result was obtained by Scheweleff ${ }^{15}$ in experiments on dogs. A. C. Klebs, ${ }^{16}$ in his history of small-pox inoculation, mentions an ancient custom among the Chinese of protecting against small-pox by putting its virus into the nose.

Busson ${ }^{17}$ describes experiments in which guinea-pigs sensitized to horse-serum were inclosed in a tight box and made to inhale a finely divided spray of horse-serum, ten times diluted, for a period of two hours or more. As far as the description can be understood there were very slight but positive signs of anaphylactic reaction. The rise of temperature within the box and the deterioration of the quality of the air must have introduced important complications into the experiment. My results confirm, in general, those of this author.

Schlecht ${ }^{18}$ records a series of researches which show that injection of a foreign serum into the body causes in the blood a great temporary increase of eosinophils, and in guinea-pigs of mast-cells as well, due to increased activity of the bone-marrow. The administration of spray

13. Dserzgowsky, S. K.: Ztschr f. Immunitätsforsch (abst.), 1910, iii, 602.

14. Blumenau, N. R.: Ibid., 1910, iv, 353 .

15. Scheweleff, P. P.: Ibid., 1910, x, 1085 (Ref. Bd.)

16. Klebs, A. C.: Bull. Johns Hopkins Hosp., 1913, xxiv, 69.

17. Busson, B.: Wien. klin. Wehnschr., 1911, xxiv, 1492.

18. Schlecht, H.: Kong. f. inn. Med., 1912, xxiv, 416; Deutsch. Arch. f. klin. Med., 1910, xc, 308; ibid., 1912, cviii, 405; Arch. f. exper. Path. u. Pharmakol., 1912, Jxvii, 137 . 
inhalations of horse-serum to guinea-pigs, either sensitized or normal, was followed by a high grade of eosinophilia localized in the lungs.

In the discussion of Schlect's paper, read before the Congress for Internal Medicine, Schittenhelm said that he had not been able to repeat the results of Friedberger, who had produced aseptic pneumonia in sensitized guinea-pigs by inhalations of serum.

Ishioka ${ }^{19}$ made injections of serum through a fine cannula directly into the trachea of sensitized guinea-pigs. Out of forty animals two died at once in anaphylactic shock; the others showed symptoms but recovered. In a few cases there was produced interstitial pneumonia with much ernphysema. In most cases there resulted true lobar pneumonia indicated by patches of infiltration which could even involve a whole lobe.

My method of bringing the serum in contact with the respiratory epithelium differed radically from that described elsewhere. Some two dozen guinea-pigs were treated in two groups; in one the treatment consisted in instilling fresh horse-serum into the nose by dropping it from a hypodermic needle; in the other the serum was breathed as a fine spray. In the first case the animal was gently held by the hand on its back; from an all-glass hypodermic syringe with easily moving piston and a coarse, blunt needle, droplets of serum to the amount of from 0.25 to 0.33 c.c. were allowed to fall into one or the other of the nostrils. As a rule, only one side of the nose was utilized at each sitting. Various animals were treated daily or at intervals of one, two or three days.

The serum spray was produced in a commercial "vaporizer" actuated from a compressed-air tank. The spray thus formed was exceedingly fine and resembled the vapor from a gently boiling teakettle. A funnel made of stiff paper was applied over the nose and mouth of the guineapig as it sat on a table. The nozzle of the spray apparatus was closely applied within the smaller but open end of the funnel. The spray was applied at intervals similar to those of the instillations and the sittings lasted, as a rule, about three minutes. The serum was often used in full strength; in dilutions of one-half or one-quarter strength the results appeared the same. Theoretical objections against this method of procedure seem invalid in the light of the reactions obtained.

Each group of guinea-pigs was composed of four subdivisions: (1) normal animals; (2) animals sensitized by the subcutaneous injection of serum; (3) unsensitized animals which had weeks before been relieved of their olfactory lobes; (4) animals which, after the removal of their olfactory lobes, had been subcutaneously sensitized.

19. Ishioka, S.: Deutsch. Arch. f. klin. Med., 1912, cvii, 500. 
SPECIAL REACTIONS TO THE NASAL INSTILLATION OF SERUM

When horse-serum is slowly dropped as described into a nostril of a guinea-pig for the first time, there is usually no disturbance whatever. The fluid is quickly sucked into the nose, and not until a considerable quantity has been introduced is there any expulsion, and this is evidently mechanical. Late in the sitting, taste and probably swallowing motions are manifested. The nasal canal in a medium-sized guinea-pig has a length of nearly $5 \mathrm{~cm}$. and therefore it is not likely that the first droplets reach the pharynx. Even with the second treatment, after two days, signs of active resistance to the instillation of serum may appear, brisk expiratory sniffing movements more or less resist the entrance of serum or expel it from the nostril.

These minor phenomena are physiologically significant but are difficult to interpret because they may occur with the instillation of normal saline or solutions of cocain at the very first administration. It was noted, however, that active resistance to the instillation of serum appeared uniformly earlier in animals with intact olfactories than in those deprived of their olfactory lobes. In animals treated every alternate day, my notes record signs of great nasal irritation in normal pigs at the second instillation, while in specimens without olfactory lobes it was not until the fourth treatment, after six days, that active reactions were produced.

Previous subcutaneous sensitization had no perceptible influence in accelerating the reactions. One definite and undoubtedly reflex response to the instillation was regularly obtained from certain animals. This was an excess of salivary secretion. While the mouths of practically all pigs which showed signs of irritation against the serum became unusually moist, in a certain number saliva would well up between and drool from the lips. This reaction held constant in the same pigs through a prolonged series of observations. The reaction was usually positive in normal pigs. It was obvious, however, that saliva accumulating in the mouth was frequently removed by swallowing and thus failed to be noted. The reaction can hardly be regarded as other than a sign of specific sensitization. It occurred both in animals previously subcutaneously sensitized and in unsensitized animals, whether with or without olfactory lobes. It did not occur through the instillation of normal salt solution even when it was constantly produced by serum. A single nasal instillation with serum evidently induces sensitization. Thus, October 11, two normal guinea-pigs each received 0.25 c.c. of serum in both nostrils. The only effect witnessed was the excitement of taste movements.

Sixteen days later, October $2 \%$, the treatment was repeated. There was now considerable nasal irritation as shown by sniffing and active 
expulsion of serum from the nose and rubbing of the nose with the paws, and in each case saliva welled from the mouth. Two days later, October 29, one of these animals received an intravenous injection of serum; there was no reaction. Five other nasal instillations were given to each pig from November 12 to November 20 . The resulting symptoms were the same as those elicited October $2 \%$, except that now the animal which had not received the intravenous injection ceased to respond to the instillation by the secretion of saliva. Finally, November 23 , both animals received intravenous injections and both died in typical shock. This account anticipates my discussion, but clearly indicates that local sensitization of the nasal mucous membrane may occur independently of and precede general sensitization.

The symptoms thus far described as resulting from nasal instillation of serum are minor reactions which it is possible to confuse with those following non-specific stimuli. But there were extraordinary results obtained in the case of a single animal, which, though obviously somewhat dependent on idiosyncrasy, are detailed because they differ only quantitatively from reactions characteristic of this group of experiments. A guinea-pig weighing $435 \mathrm{gm}$. was treated by the nostrils every second day. During the tenth treatment, eighteen days after the first, the animal suddenly choked; loud rattling râles with occasional cough accompanied the deep and labored respiration. The phenomena strongly suggested those of the severest form of bronchial asthma in man. It was several hours before the pig recovered sufficiently to eat. It had been noticed that spasmodic partial closure of the nostril had resisted the intake of serum. Subsequent administrations of serum each second day provoked similar though milder symptoms, an excessive salivary secretion becoming a relatively more prominent reaction. The symptoms could not have been due to the flow of serum directly into the trachea, for they appeared while still too small a quantity of serum had been applied. Later results with other animals leave no doubt as to the anaphylactic character of the disturbance.

\section{THE EFFECT OF THE INHALATION OF SERUM SPRAYS}

The statement was made in the beginning that the initial exhibition of vaporized serum, according to the method described, provoked no symptoms whatever. Guinea-pigs previously sensitized by subcutaneous injection reacted apparently as negatively to the inhalation as did normal animals.

A remarkable difference, however, presented itself in the behavior of those guinea-pigs which received the serum inhalation after a course of serum instillations by the nostril. In these cases there was an immediate response to the first inhalation in the form of a violent 
dyspnea, with occasional cough, asthmatic in its urgency but characterized by rapid respiratory movement. The attack would develop suddenly within about a minute of beginning inhalation and would not subside for from thirty minutes to several hours. Unfortunately no attempt was made to determine whether a phase of antianaphylaxis succeded recovery from the attack of dyspnea. Repetitions of inhalation at intervals of two days or more invariably provoked the same response.

EXPERIMENT 18.-Two young pigs were treated by instillation of serum in the nose every third and every fourth day from May 28 to July 12. Serum inhalations were given to one July 17, and to the other August 7. Both animals exhibited the reaction described, namely, violent, rapid dyspnea, interrupted with occasional deep breaths and cough.

These, together with subsequent observations, make it clear that local sensitization of the nasal mucous membrane to horse-serum may be induced without the excitement of any very marked reaction. An animal thus peripherally sensitized responds immediately to serum inhalation with characteristic dyspnea, while one sensitized subcutaneously does not. My friend Dr. Hillkowitz kindly tested the blood drawn from the heart of one of the animals described, for precipitins to horseserum. The dilutions used were $1: 1,000$ and $1: 10,000$. The results were negative, as might have been expected from the similar observations of Rosenau and Anderson. ${ }^{20}$ An excellent opportunity seemed presented in these animals to determine whether the olfactory mechanism played any rôle in the serum reactions.

EXPERIMENT 19.-A female pig, $645 \mathrm{gm}$., which had regularly responded to the inhalation, had its olfactory nerves divided August 25. Four days later, and during subsequent exposures, the serum inhalations produced symptoms identical with those produced when the olfactory nerves were intact, though possibly the latent period of reaction was longer. September 2 the olfactory lobes were excised in this pig without special reaction (because of previous section of the nerves). Two days later a serum inhalation provoked the characteristic dyspnea which began after the vaporization of thirty or forty drops of serum. September 10 this animal succumbed, in less than five minutes, to the intravenous injection of 0.5 c.c. of serum.

It was clear in this case, and abundantly confirmed later, that the peripheral application of serum not only sensitized in a peculiar way the peripheral respiratory epithelium but produced general sensitization as well. These results were to have been anticipated from the findings of other observers who used different methods. General body sensitization develops gradually during a course of local treatment with serum and apparently is preceded by the acquisition of local anaphylaxis. An effort was made to trace the development of the reactions of local and general anaphylaxis.

20. Rosenau and Anderson: Bull. Hyg. Lab., U. S. P. H. S., 1906, No. 29, p. 35. 
ExPeriment 20.-Two normal male pigs, weighing $360 \mathrm{gm}$. each, October 11 were made to inhale, with intermissions, for about ten minutes the vapor of a 50 per cent. dilution of serum. There was slight temporary dyspnea, undoubt. edly mechanical in origin and due to the long exposure to the vapor (the usual treatment occupied three minutes or less and the specific reaction commonly occurred within a minute or two). October 26 , fifteen days later, the pigs having increased in weight, a similar less-prolonged treatment was given. There was no specific reaction, although Pig 1 breathed hard for a while ten minutes later. October 29 , three days after the second and eighteen after the first inhalation, Pig 2 received, without ether, 0.5 c.c. of serum intravenously. There was no reaction. November 12 both pigs were again sprayed with serum of 50 per cent. dilution. Almost at once Pig 1 , which had not received the intravenous injection, was seized with violent, rapid panting. This passed off in about fifteen minutes. Three days later in the morning this pig was found dead. I cannot account for the fatality except as a result of the treatment combined possibly with low resistance to the cool air of the night. Necropsy showed the olfactory lobes apparently much softened. The lungs were collapsed and congested but without hemorrhagic areas. Pig. 2, which had received intravenous injection October 29, received four serum-inhalations from November 15 to November 20 . No dyspnea was caused by either treatment. This animal was given injection of serum by the vein November 23, and died with violent convulsive and bucking seizures.

These observations show that a single inhalation of serum by a normal guinea-pig provokes, when repeated fifteen days later, hardly any perceptible anaphylactic response. A third spraying, performed seventeen days after the last, produces a well-marked reaction. Intravenous injection of serum during these observations may have prevented, it certainly did not exaggerate, the reactions. It was found, as might have been expected, that guinea-pigs treated in precisely the same manner showed more or less individual differences in behavior. In contrast with the results of the last series of experiments, the following observation shows that possibly response to the local application of the antigen may be intensified by previous general sensitization.

Experiment 21.-Male, weight $570 \mathrm{gm}$. Olfactory lobes removed August 26 and the space left filled with melted paraffin. Sensitized subcutaneously with 0.33 c.c. of serum August 29. Received a prolonged inhalation of serum spray September 25, followed by no specific reaction. Inhalation was given again October 10, fifteen days later. A violent rapid dyspnea, which had not dis. appeared after an hour, immediately resulted. The treatment was repeated three times on alternate days, with identical response except that the latent period of reaction increased to a minute or two.

This experiment demonstrates again that response to the inhalation. does not demand an intact olfactory apparatus.

I will now review rapidly the history of eighteen guinea-pigs, including individuals which were subcutaneously sensitized or normal and with olfactory lobes intact or removed. Half were treated primarily with instillations of serum into the nose and half with serum inhalations. Each group was again subdivided into two parts; the animals of one subgroup had serum dropped into the nose for four times on alternate days and those of the other for four times every fourth day. 
The result was more or less active reaction with minor symptoms such as have already been described. After a resting interval of twelve days by the first group and of six days by the second group, which followed the last treatment in each, all of the nine "instillation" pigs were again given serum by the nose. To the local symptoms of nasal irritation and salivary secretion in certain animals was now added a more general reaction marked by more or less obvious dyspnea together with rattling, apparently bronchial râles. Of the two pigs in which the latter symptoms appeared, both had been subcutaneously sensitized and one had lost its olfactory lobes. Both râles and dyspnea were manifested only by animals which had received serum by the nose every fourth day. It is worth noting that when the group of animals treated in four sittings by serum dropped into the nose were given a like treatment eighteen days after the first dosage, the anaphylactic response was much more marked in animals which had received the preliminary instillations every fourth day.

In a parallel series of observations carried out with spray-inhalations, the reverse was noted; the strongest reactions occurred in animals receiving the four initial inhalations on alternate days. Five of the "instillation pigs" were given inhalations of serum on the day following the treatment which had produced so marked a reaction. The result was the production of a marked specific dyspnea in two of these animals. It is worth noting that of two pigs which had received no serum subcutaneously and from which the olfactory lobes had been removed, one responded by dyspnea to the spray and one did not. Of the two pigs not operated on, likewise without subcutaneous serum, neither responded. This experiment shows again that local sensitization of one part of the respiratory tract involves sensitization of the rest, though, as will be pointed out presently, there are marked local signs which distinguish the dyspnea produced by inhalation of serum in spray from that caused by its instillation in the nose.

Rapid dyspnea was the one sign of anaphylaxis observed in the inhalation experiments. It could be produced in nearly all animals, but some individuals responded much more readily than others. One animal which was made dyspneic by the inhalation, failed to react when sprayed daily, until the eighth day, when it responded again. In general, the daily administration of inhalations produced no response, though one pig which had received its first inhalation about two weeks previously responded each time to inhalation given every forty-eight hours. Of four animals which had received four sprayings on alternate days, from October 10 to 16 , only one had shown marked reaction. They received another inhalation October 26 and each responded strongly - in fact the dyspnea in two cases was of desperate urgency. 
Of these animals only two had been sensitized with serum subcutaneously. One of them had been deprived of olfactory lobes.

Five pigs which had received four inhalations from October 10 to 22 were likewise treated with the spray, October 26 , but all responded very feebly. These animals were again given inhalations, November 2 , and the dyspneic response was decidedly more vigorous though still much less marked than in the group treated after a longer passive interval. These results suggest, of course, the similar findings when anaphylaxis is studied through subcutaneous injections given at close intervals.

In a previous experiment it was shown that guinea-pigs sensitized by serum dropped into the nose could be made dyspneic at once by subjecting them to a spray of serum. The converse of this experiment was now performed. Four pigs that had reacted to the spray by dyspnea were given serum by the nose. In one there was reaction with only minor symptoms, but in the other three after long latent periods, five to ten minutes, rattling râles developed, which seemed to emanate from both the bronchi and the nose; there was also more or less cough.

As already mentioned, there is a marked difference in the quality of the anaphylactic response to the serum spray and serum instillation. In animals subjected to the former there are no râles, however violent the dyspnea. In animals responding strongly to the instillation, râles, which may be very loud and lasting, may occur with a variable element of dyspnea. The difference depends, probably, on the volume of secretion excited; that is, when a pig sensitized by instillation responds to the spray it is with a dry dyspnea; when a pig sensitized by the spray responds to instillation of serum droplets it is with a moist dyspnea. In later observations it was found that, in the shock resulting from the toxic intravenous injection, the influence of the "local sign" of the site of sensitization still held good. A pig which had been sensitized by the spray breathed very fast in its anaphylactic throes but developed no râles. Others which had been sensitized by instillation developed râles with, usually, less rapid breathing under the same conditions.

All the animals employed in these experiments were finally submitted to the supreme test of intravenous injection of serum. By this means it was sought to determine to what degree sensitization of the body could be developed by the peripheral application of serum, if at all, and also whether such application could essentially modify sensitization already induced by serum injected under the skin. The intravenous injections were given from twenty-nine to thirty days after beginning of the local treatment and after general sensitization had certainly been secured. Of the twenty and more animals available, four survived the first intravenous injection of serum. 
Of eleven pigs treated by nasal instillation of serum three survived the first "toxic" injection. One of these belonged to a group of three from which the olfactory nerves and lobes had been removed but which had received no serum subcutaneously. This animal had been given serum by the nose four times at intervals of four days, from October 9 to October 21, and again on October 2\%. The creature had manifested plain signs of sensitization. Treated with serum spray, October 28 , it became violently dyspneic. It was given 0.25 c.c. of serum intravenously, November 10 . The animal was badly shocked in a manner peculiarly different from the ordinary anaphylactic seizures, that is, there were no clonic convulsions but the respiration was exceedingly rapid and made audible by râles. After about an hour, when the animal had apparently recovered, it suddenly suffered a fleeting twisting convulsion of the body. Thirteen days later, November 23, this animal received a second intravenous injection of more than 0.5 c.c. of serum. Great shock resulted with, at the outset, no sign of convulsion except clonic twistings. The respiration was very rapid and bronchial and nasal râles were loud. Finally, after sixteen days, December 9 , a third intravenous injection of about 0.75 c.c. of serum was given. There was no anaphylactic reaction but great muscular weakness. Slight clonic twitchings set in after several hours, the weakness increased and the animal died in about twenty hours. Animals of this class also differed from those in ordinary anaphylactic reaction in that they appeared to be conscious even while lying on the side in deepest shock.

of the other two "instillation pige" that survived intravenous injection, both belonged to a group of three normal animals which had neither been operated on nor received serum subcutaneously. Their local treatment was similar to that of the last animal described except that neither was sprayed. Both of these animals, especially the second, had manifested slight but apparently unmistakable anaphylactic reaction to serum dropped into the nose. The first of the two was given 0.33 c.c. of serum intravenously November 8 . The creature remained phenomenally quiet throughout the injection. There was no reaction whatever. The injection was repeated with 0.5 c.c. of serum, November 24: result, violent convulsions and typical death. I am inclined to interpret this case as further evidence that local sensitization may be achieved without producing any demonstrable general sensitization. The second surviving pig of this lot had especially reacted to instillation of serum by abundant secretions of saliva, an apparent sign of sensitization. Given an intravenous injection of 0.5 c.c. of serum, November 23 , there was no reaction whatever (the animal was a female far advanced in pregnancy). Sixteen days later, the animal having borne a litter of young a week previously, a second intravenous injection of nearly 0.5 c.c. of serum 
was given. 'There was no reaction except for rapid, jerky breathing and a few râles. Special stress deserves to be laid on the fact that this animal had achieved its wonderful power of self-protection by a course of treatment which had provoked exceedingly slight signs of anaphylaxis.

The single "inhalation-pig" that survived an intravenous injection of serum belonged likewise to a group of three which had neither been subcutaneously sensitized nor operated on. This animal did not react to repeated inhalation treatments until several had been given; then the response was slight but positive as to anaphylaxis. November 8 , 0.5 c.c. of serum was given intravenously. The reaction was moderate but distinct. At the outset respiration was deepened and there were slight convulsive movements. Then the breathing became very rapid, interrupted by occasional very deep breaths, and so continued for half an hour. 'There were no râles as in the instillation pigs. November 24, sịteen days later, the treatment was repeated. Deep, rapid respiration with strangling cough came on at once. The animal died in five minutes without having exhibited respiratory râles or any convulsions.

It will be noted that none of the animals which had been previously sensitized by the subcutaneous administration of serum survived the toxic injection. The conclusion is that general sensitization so produced is not essentially modified by the efficient antigen applied to the peripheral epithelium, although general sensitization is undoubtedly achieved in this way. That this non-interference of the serum, peripherally applied, with the previous general sensitization, is not dependent on the time intervals of its application, seems shown by the fact that six "instillation" and four "spray" pigs received a course of seven daily treatments extending to within three days of the toxic injection; but only one survived it: In other cases the interval between the last local treatment and the toxic injection extended to more than twelve days. It is clear also that the olfactory apparatus, as far as represented by the olfactory lobes and intracranial nerves, is not essential to the systemic effects of serum locally applied. In fact, the normal animals apparently resisted general sensitization in an active way except as to the secretion of saliva. Of a group of animals reacting in about the same way to local treatment, one might survive and the others succumb to the toxic injection.

There was nothing in the results obtained by me to suggest any change in the respiratory epithelium resembling the "phenomenon of Arthus" (increasingly morbid local changes following repeated subcutaneous injections), which has been carefully investigated by Nicolle. ${ }^{21}$ This subject was not, however, definitely investigated.

21. Nicolle, M.: Ann. de l'Inst. Pasteur, 1907, xxi, 128. 
The statements of Friedberger, Ishioka and Busson in regard to pneumonic changes in the lungs of sprayed animals were, to a degree, confirmed. Such lungs at necropsy frequently revealed air-free hemorrhagic areas of limited extent. The affected portions when removed would sink in water, but they were soft and not resistant as in pneumonic consolidation. The post mortem change was by no means constant among sprayed pigs and was also found in animals dying from toxic injections, which had not been sprayed at all.

\section{POSSIBLE ATROPHY OF THE OLFACTORY EPITHELIUM}

Because of its importance I venture mention of a theme on which investigation was started but abandoned early in this work. In animals deprived of their olfactory lobes and even in some under other and functional conditions, there seemed to be a well-marked atrophy of the olfactory mucous membrane as disclosed by cutting away the roof of the nasal cavities. The subject was pursued no further than to give a basis for special research.

THE EFFECT ON TUBERCULOUS GUINEA-PIGS OF TUBERCULIN APPLIED TO THE PERIPHERAL EPITHELIUM

It was, of course, a surface thought that some useful therapeutic purpose might be served by treating a systemic affection through the peripheral epithelium. Tuberculous guinea-pigs were the subjects and the old tuberculin of Koch was the remedy. Six young guinea-pigs were inoculated with what proved to be a very attenuated culture of tubercle bacilli, kindly furnished me by Dr. G. B. Webb of Colorado Springs, July 25. Three of the animals were inoculated in the peritoneum and three beneath the skin. Two were used as controls and four were treated. The treatment consisted in dropping into the mouth of two subjects, in such a way as to excite the maximum taste-sensations, or in instilling into the nose (two subjects) dilutions of old tuberculin usually of from 0.5 to 1 per cent. Treatment given was from every, day to every fourth day. Treatments were begun more than six weeks before the inoculations and were continued for more than two months afterward. Superficial observation could detect no particular reaction to the treatments except the excitement of slight dyspnea by spraying (which was practiced later). One of the treated pigs had to be killed, October 23, because of a tuberculous swelling occluding the urethra. The other pigs all gained in weight and were sacrificed for specific purposes nearly four months after their inoculation with tubercle bacilli. Post-mortem examination left no manner of doubt as to the effect of treatment: The extent and intensity of the tuberculous processes were much greater in the treated animals than in the controls. 


\section{DISCUSSION AND SUMMARY}

Certain facts recorded in this investigation seem to furnish evidence which must be considered in further discussions of the old problem of the physiological requirements in ventilation. The trend of scientific opinion has lately been to ascribe the deleterious properties of rebreathed air solely to the untoward physicial conditions of heat and humidity usually involved. Rosenau and $\mathrm{Amoss}^{22}$ recently published experiments tending back to the old "chemical view" of the noxiousness of rebreathed air. Their work has been controverted in literature not available to me.

The observations, detailed above, on the desensitization of guineapigs when exposed to the smell of horses, seem to establish beyond question, if such proof were needed, that animal effluvia when inhaled can produce at once profound systemic disturbance. It is usually taken for granted that "ventilation" has the same biological import for all people. On the contrary, it may well be that people suffering from various ailments may find in rebreathed air noxal elements specifically related to their infections (as did my guinea-pigs in the stable). Such a conception, of course, vastly complicates the biological consideration of ventilation. For many years I have noticed in carrying out physical examinations of the sick that the subjects of pulmonary tuberculosis appeared especially prone to aroid, as far as possible, the inhalation of the examiner's breath; it has seemed to me an instinctive effort toward specific self-protection.

Evidence has been brought forward which indicates a peculiar immunological relation between the central nervous system, or at least the brain, and the body. The brain can be sensitized and desensitized an indefinite number of times without essentially changing the susceptibility of the body (Besredka records three desensitizations in one animal within a few days). This desensitization of the brain after horse-serum injections may be brought about by a number of different agencies, ${ }^{22}$ the specific antigen, as used by Besredka, or something allied to it and contained in the effluvia of horses, or, as I have shown, by cutting the olfactory nerves, lacerating the brain tissue or even by setting up mechanical vibrations in it. Rapid desensitization of the brain is marked by a more or less profound nervous shock followed by a brief period of antianaphylaxis during which the animal is absolutely protected from the poisonous antigen. The nerve impulses producing this remarkable somatic change must operate on the living tissues. It appears probable that these nerve impulses cause the tissues, as it were, to open their receptors for the specific antibody in the blood.

22. Rosenau and Amoss: Jour. Med. Research, 1911, xxv, 35.

23. Kolle and Wassermann: Handbuch der pathogenen Mikroorganismen, ii, Part 2, p. 1086. 
If this "allergin" is removed from the circulation an animal has become essentially normal as regards reactivity to that antigen. Fixed in the tissues the allergin combines with more or less antigen contained therein and we witness a degree of shock proportional thereto. It is significant that all observers seem to agree that the allergin diminishes greatly or disappears from the circulation during the phase of antianaphylaxis. ${ }^{24}$ According to the conception presented here the allergin is released from the tissues after a longer or shorter interval and, when returned to the circulation, susceptibility to the antigen is restored.

The widely accepted view of Friedberger ${ }^{25}$ that antianaphylaxis depends on the saturation of the anaphylactic antibody with the newly introduced antigen cannot explain the condition when caused by brain mutilation; nor does this author's conception of the two states of nonspecific and specific antianaphylaxis clear the matter. In fact, Bessau ${ }^{26}$ makes a strong stand against Friedberger's theory and concludes that antianaphylaxis results from a reaction of the organism through which its irritability is depressed as regards the anaphylactic poison. In the masterly and lucid monograph of the Vaughans ${ }^{27}$ it is held that the important factor which determines the refractory state of the reinjected animal "is the changed relation between the amount of ferment and the substrate," that is, the small amount of antibody remaining in the blood of the antianaphylactic animal becomes functionally inoperative in the presence of a great excess of antigen. This view, also, fails to account for the facts I have detailed. Evidence has been developed to show that the irritability of the brain, using this term in a broad physiological sense, is to an extraordinary extent dependent on olfactory stimuli. The teleological interpretation of these coordinations is irresistible. An animal smells many agents to which his body is sensitized and which, if eaten, would act as poisons per se, but through the olfactory sense the brain is sufficiently stimulated by the odor of the antigen to discharge impulses which set up in the body a state of antianaphylaxis during which the intrinsically poisonous substance may be ingested with impunity. The reaction of my guinea-pigs in the stable gives substantial support to such a conception. The possible relations of these conceptions to human physiology, psychology and surgery are obvious. The experiments with local applications of serum to the nose or by inhalation of a spray show clearly that sensitization of the respiratory epithelium develops after a definite latent period whose length does

24. See the valuable paper by Anderson and Frost, Bull. Hyg. Lab., U. S. P. H. S., 1910, No. 64 .

25. Friedberger: Ztschr. f. Immunitätsforsch., 1909, ii, 208.

26. Bessau, G.: Centralbl. f. Bakteriol., 1911, lx, 637.

27. Vaughan, V. C., Vaughan, V. C., Jr., and Vaughan, J. W.: Protein Split Products in Relation to Immunity and Disease, 1913, p. 312. 
not appear to be influenced by previous general sensitization of the body.

In contrast with this relative independence of central and peripheral sensitizations it is found that sensitization of the nasal respiratory tract involves the pulmonary epithelium, and vice versa, though each reacts with its own "local sign." The local reactions of the animal inevitably suggest that local anaphylaxis is a state of active resistance against absorption of the antigen. Transferring this idea to bacterial focal infections in the interior of the body, we get a more reasonable explanation of the beneficial results which often follow the injection of antigenous bacterial bodies; these can come into intimate contact with tissues capable of antibody formation from which the bacteria of the infective foci are debarred. Finally, the proof is once more absolute that serum dropped into the nose or given by inhalation sensitizes the body irrespective of the olfactory apparatus. The obvious explanation of the fact is that the antigen is absorbed by the circulation, as is supposed to be the case when serum is introduced into the rectum. ${ }^{28}$ But "obvious explanations" are especially dangerous. Unfortunately, I have not been able to show that such peripheral application of the antigen in any way influences the reactions of a subcutaneously sensitized animal to the toxic intravenous injection. This seems a surprising fact in view of the accepted teaching that repeated injections of sublethal doses of serum produce in an animal a resistance, if not full immunity. That some peculiar status is occupied by the phenomena induced by application of serum to the respiratory epithelium seems shown by the fact that in two cases unsensitized guinea-pigs, from one of which the olfactory lobes had been removed, were somatically sensitized by this means and that they thereafter withstood several toxic injections separated by intervals of about two weeks. Experimental analogies have been presented for the anaphylactic phenomena of hay-fever and bronchial asthma. It is shown that both a general and a local sensitization are to be considered, interdependent, but each having an autonomy.

\section{CONCLUSIONS}

Briefly summarized, the following conclusions may be drawn:

1. Guinea-pigs sensitized to horse-serum may be desensitized by residence in a horse-stable. It is probable that this reaction may be rapidly achieved through the olfactory sense or more slowly by absorption through the respiratory mucous membrane. The period of antianaphylaxis is of less than two days' duration. The converse of this,

28. Vaughan, V. C.: Vaughan, V. C., Jr., and Vaughan, J. W.: Protein Split Products, 1913, p. 259. 
sensitization of normal guinea-pigs in stable air, I have not been able to achieve.

2. Removal of part of the brain of a sensitized guinea-pig produces much more severe shock than the same amount of injury in a normal animal. This shock is apt to be followed by a period of antianaphylaxis of short duration.

3. Section of the olfactory nerves within the cranial cavity preceding the brain operation by a day or more abolishes the tendency to shock. Such nerve section in the normal animal also seems to reduce the shock arising from definite brain injury.

4. Depression of the olfactory sense may be produced through cocain and the symptoms of poisoning with this drug resemble those of anaphylaxis.

5. The body as a whole may be sensitized through the peripheral application of horse-serum after a definite latent period. The time required to sensitize the peripheral epithelium has not been found to be materially altered by previous general sensitization. A normal animal sensitized by local treatment may resist large intravenous injections of serum repeated at intervals of two weeks.

6. Sensitization of one area of the respiratory opithelium involves sensitization of the rest, though the local signs of expression are different.

7. The evidence indicates that local anaphylaxis, induced through the periphery, precedes the development of general sensitization.

8. Tuberculous guinea-pigs were made worse when treated by instillations or sprays of old tuberculin.

Besides the expression already made regarding Dr. Powell, it is a pleasure to acknowledge my indebtedness to my colleagues, Dr. W. C. Mitchell and Dr. P. Hillkowitz, for many favors, and to Dr. Auer of the Rockefeller Institute for hints as to technic.

1360 Vine Street. 